FIG. 1

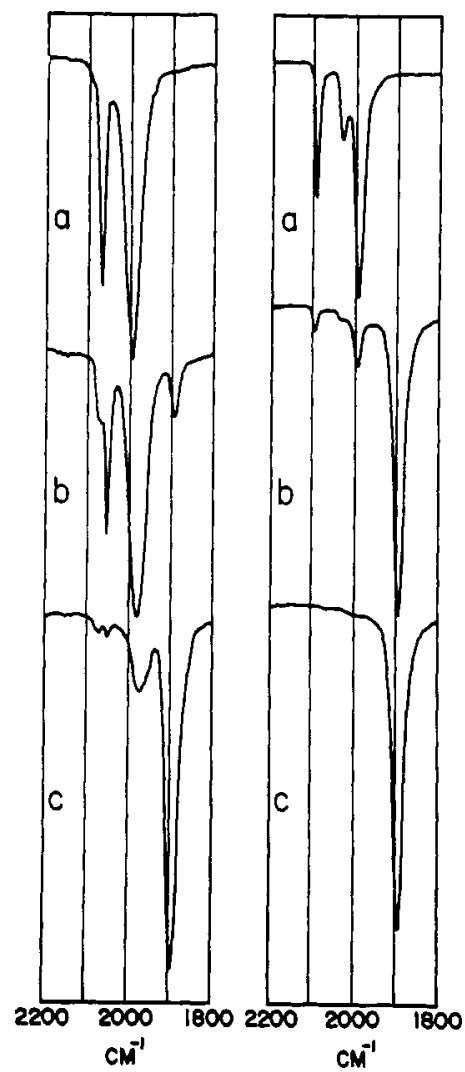

Figure 1. DMF solutions: (a) $0.01 M \mathrm{Hg}\left[\mathrm{Co}(\mathrm{CO})_{4}\right]_{2}$; (b) 0.01 $M \mathrm{Hg}\left[\mathrm{Co}(\mathrm{CO})_{4}\right]_{2}+0.01 M\left(\mathrm{C}_{2} \mathrm{H}_{5}\right)_{4} \mathrm{NBr}$; (c) $0.01 \mathrm{MHg}\left[\mathrm{Co}(\mathrm{CO})_{4}\right]_{2}$ $+0.05 M\left(\mathrm{C}_{2} \mathrm{H}_{5}\right)_{4} \mathrm{NBr}$.

Figure 2. Acetonitrile solutions: (a) $0.01 \mathrm{M}\left(\mathrm{C}_{6} \mathrm{H}_{5}\right)_{8} \mathrm{SnCo}(\mathrm{CO})_{4}$; (b) $0.01 M\left(\mathrm{C}_{6} \mathrm{H}_{5}\right)_{3} \mathrm{SnCo}(\mathrm{CO})_{4}+0.01 M\left(\mathrm{C}_{2} \mathrm{H}_{5}\right)_{4} \mathrm{NBr}$; (c) $0.01 M$ $\left(\mathrm{C}_{6} \mathrm{H}_{5}\right)_{3} \mathrm{SnCo}(\mathrm{CO})_{4}+0.05 \mathrm{M}\left(\mathrm{C}_{2} \mathrm{H}_{5}\right)_{4} \mathrm{NBr}$

Displacement reactions are not restricted to the group IIB metals. A particularly good example involving a group IV metal is provided by $\left(\mathrm{C}_{6} \mathrm{H}_{5}\right)_{3} \mathrm{SnCo}(\mathrm{CO})_{4}$ in acetonitrile. Conductivity and infrared studies ${ }^{2}$ have established that this compound was not significantly dissociated in the pure solvent at $0.01 \mathrm{M}$. The infrared spectrum (Figure 2a) did not differ greatly from that observed in cyclohexane. ${ }^{5}$ Upon addition of an equimolar quantity of $\left(\mathrm{C}_{2} \mathrm{H}_{5}\right)_{4} \mathrm{NBr}$ a strong band at $1895 \mathrm{~cm}^{-1}$ was observed with a corresponding decrease in the intensity of the other bands (Figure 2b). A fourfold excess of bromide ion resulted in a single strong band at $1895 \mathrm{~cm}^{-1}$ (Figure 2c) corresponding to complete conversion to $\mathrm{Co}(\mathrm{CO})_{4}{ }^{-}$. With $\mathrm{DMF}$ as solvent, experiments employing a fourfold excess of bromide ion resulted in partial formation of $\mathrm{Mn}(\mathrm{CO})_{5}{ }^{-}$and $\mathrm{Mo}-$ $(\mathrm{CO})_{3} \mathrm{C}_{5} \mathrm{H}_{5}{ }^{-}$with $\left(\mathrm{C}_{6} \mathrm{H}_{5}\right)_{3} \mathrm{SnMn}(\mathrm{CO})_{5}$ and $\left(\mathrm{C}_{6} \mathrm{H}_{5}\right)_{3} \mathrm{Sn}$ $\mathrm{Mo}(\mathrm{CO})_{3} \mathrm{C}_{5} \mathrm{H}_{5}$, while $\left(\mathrm{C}_{6} \mathrm{H}_{5}\right)_{3} \mathrm{SnFe}(\mathrm{CO})_{2} \mathrm{C}_{5} \mathrm{H}_{5}$ was unaffected.

The foregoing observations may be interpreted as nucleophilic displacements of the transition metal carbonyl anion from the main group metal by halide ion, e.g.

$$
\left(\mathrm{C}_{6} \mathrm{H}_{5}\right)_{3} \mathrm{SnCO}(\mathrm{CO})_{4}+\mathrm{Br}^{-} \rightleftharpoons\left(\mathrm{C}_{8} \mathrm{H}_{6}\right)_{3} \mathrm{SnBr}+\mathrm{Co}(\mathrm{CO})_{4}^{-}
$$

From kinetic studies with organic halides Dessy, Pohl,

(5) D. J. Patmore and W. A. G. Graham, Inorg. Chem., 6, 981 (1967). and King ${ }^{6}$ established an order of nucleophilicities for the metal carbonyl anions employed in this work, viz. $\mathrm{Fe}(\mathrm{CO})_{2} \mathrm{C}_{5} \mathrm{H}_{5}^{-} \gg \mathrm{W}(\mathrm{CO})_{3} \mathrm{C}_{5} \mathrm{H}_{5}^{-}>\mathrm{Mo}(\mathrm{CO})_{3} \mathrm{C}_{5} \mathrm{H}_{5}^{-}$ $\cong \mathrm{Mn}(\mathrm{CO})_{5}^{-}>\mathrm{Co}(\mathrm{CO})_{4}^{-}$. The behavior of the compounds examined thus far is in qualitative agreement with their findings. In the triphenyltin series, with a fourfold excess of $\left(\mathrm{C}_{2} \mathrm{H}_{5}\right)_{4} \mathrm{NBr}$ in DMF, the bromide ion was apparently not a sufficiently strcng nucleophile to displace $\mathrm{Fe}(\mathrm{CO})_{2} \mathrm{C}_{5} \mathrm{H}_{5}{ }^{-}$. Partial cisplacement occurred for $\mathrm{Mo}(\mathrm{CO})_{3} \mathrm{C}_{5} \mathrm{H}_{5}{ }^{-}$and $\mathrm{Mn}(\mathrm{CO})_{5}^{-}$ whereas with $\mathrm{Co}(\mathrm{CO})_{4}{ }^{-}$displacement was complete even in acetonitrile.

Although nucleophilic displacement of a transition metal group by halide ion has not been previously described as such, it seems likely that this process was responsible for the formation of $\mathrm{C}_{5} \mathrm{H}_{5} \mathrm{M}(\mathrm{CO})_{3} \mathrm{MgBr}$ (THF) (and presumably $\left(\mathrm{C}_{2} \mathrm{H}_{5}\right)_{3} \mathrm{GeBr}$ ) by the action of excess $\mathrm{MgBr}_{2}$ on $\left(\mathrm{C}_{2} \mathrm{H}_{5}\right)_{3} \mathrm{GeM}(\mathrm{CO})_{3} \mathrm{C}_{5} \mathrm{H}_{5}(\mathrm{M}=\mathrm{Mo}$, W) in THF. ${ }^{7}$ Displacement of one transition metal carbonyl anion by another that is a stronger nucleophile has been observed in several cases. For example, electrochemically generated $\mathrm{Fe}(\mathrm{CO})_{2} \mathrm{C}_{5} \mathrm{H}_{5}-$ reacted with $\left(\mathrm{C}_{6} \mathrm{H}_{5}\right)_{3} \mathrm{SnMo}(\mathrm{CO})_{3} \mathrm{C}_{5} \mathrm{H}_{5}$ to produce $\left(\mathrm{C}_{6} \mathrm{H}_{5}\right)_{3} \mathrm{SnFe}(\mathrm{CO})_{2}$ $\mathrm{C}_{5} \mathrm{H}_{5}{ }^{8}$

From the limited number of systems examined in this work it would appear that displacement reactions of the type described are more common than previously anticipated. Some practical considerations follow from these results. First, the presence of soluble halides in the synthesis of metal-metal bonded compounds containing metal carbonyl groups that are weak nucleophiles may limit the conversion to the desired product by a process such as that depicted in eq 1 . Secondly, the presence of a particular transition metal carbonyl group in a complex heterometallic molecule may be detectable by the characteristic infrared absorptions of the displaced anion. Finally it may be anticipated that a variety of nucleophiles will behave similarly. The scope of this type of reaction is currently under study.

Acknowledgment. It is a pleasure to acknowledge financial support from the National Science Foundation and the Petroleum Research Fund along with generous gifts of chemicals from Ethyl Corporation and Climax Molybdenum Company.

(6) R. E. Dessy, R. L. Pohl, and R. B. King, J. Am. Chem. Soc., 88, 5121 (1966).

(7) A. Carrick and F. Glockling, J. Chem, Soc, A, 913 (1968).

(8) R. E. Dessy and P. E. Weissman, J. Am. Chem. Soc., 88, 5129 (1966)

James M. Burlitch

Department of Chemistry, Cornell University Ithaca, New York 14850

Received March 31, 1969

\section{A Dihydroxo-Bridged Ferric Dimer}

Sir:

Recent investigations have produced ${ }^{1-3}$ a large number of dimeric complexes containing the oxo-bridged structural unit $\mathrm{Fe}_{2} \mathrm{O}^{4+}$. Here we report the isolation

(1) H. Schugar, C. Walling, R. B. Jones, and H. B. Gray, J. Am Chem. Soc., 89, 3712 (1967), and references therein.

(2) W. M. Reiff, W. A. Baker, Jr., and N. E. Erickson, ibid, 90, 4794 (1968), and references therein.

(3) J. Lewis, F, E. Mabbs, and A. Richards, J, Chem. Soc., A, 1014 (1967). 
and characterization of $\left[\mathrm{Fe}(\mathrm{pic})_{2} \mathrm{OH}\right]_{2}$, which apparently is the first example of a crystalline iron(III) dimer which utilizes dihydroxo bridging in its coordination structure.

Anderegg has previously demonstrated ${ }^{4}$ by redox potentiometry that ferric ion forms $1: 1$ and $1: 2$ complexes with picolinate; the latter complex hydrolyzes to $\left[\mathrm{Fe}(\mathrm{pic})_{2} \mathrm{OH}\right]$, which dimerizes at relatively low chelate concentrations $\left(>10^{-4} M\right)$. We have isolated the dimer as a yellow-green microcrystalline powder by raising the $\mathrm{pH}$ of fairly concentrated chelate solutions to about 4 with $\mathrm{HCO}_{3}{ }^{-}\left(\mathrm{Fe}^{3+}\right.$ :picolinic acid: $\mathrm{HCO}_{3}{ }^{-}=$ $1: 2: 3$ with $\left[\mathrm{Fe}^{3+}\right]>0.1 M$ ). The preferred method of preparation utilizes slow base generation from the hydrolysis of urea. A typical preparation involved heating a solution of 0.01 mole of $\mathrm{FeCl}_{3} \cdot 9 \mathrm{H}_{2} \mathrm{O}, 0.02$ mole of picolinic acid, and 0.01 mole of urea in $200 \mathrm{ml}$ of water at $90-95^{\circ}$ for 1 day. The resulting yellow-green prismatic needles were separated from the hot solution, washed with water, and dried at $100^{\circ}$ (yield 60-70\%); the crystals become contaminated with a red substance if a stoichiometric amount of urea is used and/or heating is continued for a period of several days. The dimeric complex is only very slightly soluble in water and in common organic solvents such as acetone, methanol, and chloroform.

The structure of dimeric complex may be inferred from infrared spectral data. The infrared spectrum of $\left[\mathrm{Fe}(\mathrm{pic})_{2} \mathrm{OH}\right]_{2}(\mathrm{KBr}$ pellet or mineral oil mull) reveals a broad, weak absorption at $950 \mathrm{~cm}^{-1}$ that is not present in the spectrum of the monomeric complex [Fe(pic) $)_{2}^{-}$ $\left(\mathrm{OH}_{2}\right) \mathrm{Cl}$. Secondly, no band between 800 and 850 $\mathrm{cm}^{-1}$ attributable ${ }^{1,6,7}$ to an oxo-bridged structural unit is observed in $\left[\mathrm{Fe}(\text { pic })_{2} \mathrm{OH}\right]_{2}$. Finally, the similarity in the absorption peaks due to the picolinate ligand in both $\left[\mathrm{Fe}(\mathrm{pic})_{2}\left(\mathrm{OH}_{2}\right) \mathrm{Cl}\right]$ and $\left[\mathrm{Fe}(\mathrm{pic})_{2} \mathrm{OH}\right]_{2}$ rules against any type of picolinate bridging in the dimer. We therefore conclude that the $950-\mathrm{cm}^{-1}$ band in $\left[\mathrm{Fe}(\mathrm{pic})_{2} \mathrm{OH}\right]_{2}$ is due to a vibrational mode associated with the $\mathrm{Fe}_{2}(\mathrm{OH})_{2}{ }^{4+}$ structural unit. Consistent with this assignment, the $950-\mathrm{cm}^{-1}$ band is not observed in a sample of [Fe(pic $)_{2}$ $\mathrm{OD}]_{2}$, which was prepared by precipitating the complex from $\mathrm{D}_{2} \mathrm{O}$. It is reasonable to assume that the band in question has shifted in the dideuterioxo-bridged complex to substantially lower frequency and is hidden under the strong absorption due to the coordinated picolinate groups.

Our interpretation of the structure of the dimeric complex derives additional support from the fact that crystals of $\left[\mathrm{Cr}(\mathrm{pic})_{2} \mathrm{OH}\right]_{2}$, which we have prepared and fully characterized, ${ }^{8}$ are isomorphous with crystals of $\left[\mathrm{Fe}(\text { pic })_{2} \mathrm{OH}\right]_{2}$; the infrared band in $\left[\mathrm{Cr}(\text { pic })_{2} \mathrm{OH}\right]_{2}$ due to the $\left[\mathrm{Cr}_{2}(\mathrm{OH})_{2}\right]^{4+}$ unit is observed at $970 \mathrm{~cm}^{-1}$.

Magnetic susceptibility data in the range $16-229^{\circ} \mathrm{K}$ for $\left[\mathrm{Fe}(\mathrm{pic})_{2} \mathrm{OH}\right]_{2},\left[\mathrm{Fe}(\mathrm{pic})_{2}\left(\mathrm{OH}_{2}\right) \mathrm{Cl}\right]$, and the known ${ }^{1}$ oxo-bridged dimer [(FeHEDTA $\left.)_{2} \mathrm{O}\right)^{2-}$ are shown in Figure 1. The formulation of $\left[\mathrm{Fe}(\text { pic })_{2} \mathrm{OH}\right]_{2}$ as a hydroxo-bridged dimer is consistent with the extent of its antiferromagnetic behavior, which is considerable

(4) von G. Anderegg, Helv. Chim. Acta, 43, 1530 (1960).

(5) Satisfactory elemental analyses have been obtained for all new compounds reported here.

(6) F. A. Cotton and R. M. Wing, Inorg. Chem., 4, 867 (1965).

(7) D. J. Hewkin and W. P. Griffith, J. Chem. Soc., A, 472 (1966).

(8) Magnetic susceptibility data for $\left[\mathrm{Cr}(\text { pic })_{2} \mathrm{OH}\right]_{2}$ in the range $16-$ $300^{\circ} \mathrm{K}$ give $J=-6 \mathrm{~cm}^{-1}$ for $g=2.00$, which falls in the range $J=$ -4 to $-7 \mathrm{~cm}^{-1}$ found for dihydroxo-bridged $\mathrm{Cr}$ (III) dimers; see A. Earnshaw and J. Lewis, J. Chem. Soc., 396 (1961).

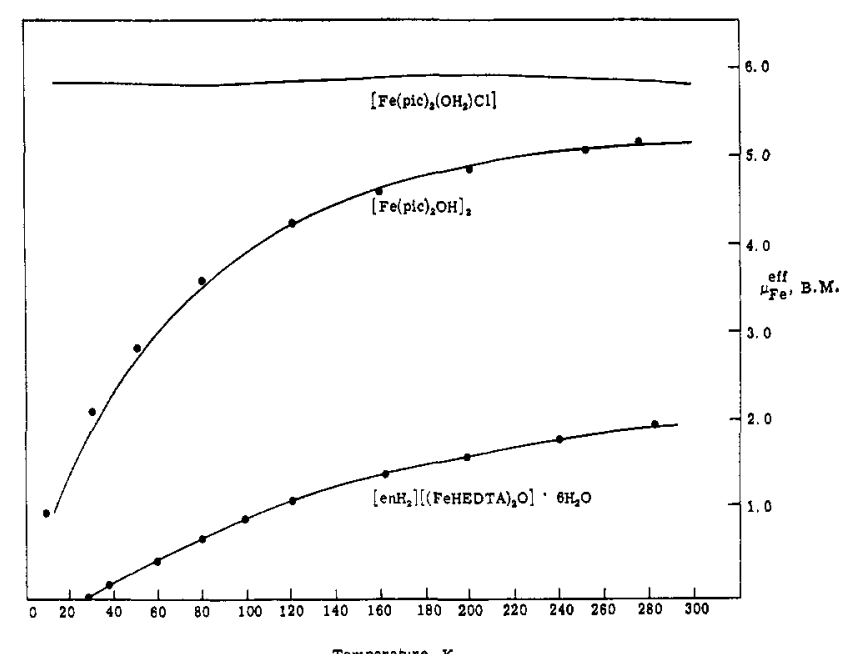

Figure 1. Temperature profiles $\left(16-299^{\circ} \mathrm{K}\right)$ of the effective magnetic moment per iron of monomeric, hydroxo-bridged, and oxobridged iron(III) complexes. The $\mu$ vs. $T$ curves represent continuous $\chi_{g}$ vs. $T$ experimental data obtained from a variable-temperature vibrating sample magnetometer. The points shown are theoretically calculated for a spin-coupled $(5 / 2,5 / 2)$ system with $J=$ $-8 \mathrm{~cm}^{-1}, g=2.0$ for $\left[\mathrm{Fe}(\mathrm{pic})_{2} \mathrm{OH}\right]_{2}$, and $J=-86 \mathrm{~cm}^{-1}, g=2.0$ for $\left[\mathrm{enH}_{2}\right]\left[(\mathrm{FeHEDTA})_{2} \mathrm{O}\right] \cdot 6 \mathrm{H}_{2} \mathrm{O}$.

relative to the reference monomeric complex but is not in the range typical ${ }^{1-3}$ of oxo-bridged structures. Assuming a spin-spin coupling model with $g=2.00$, an excellent fit of the magnetic data is obtained for $J=-8$ $\mathrm{cm}^{-1}$ in the case of $\left[\mathrm{Fe}(\mathrm{pic})_{2} \mathrm{OH}\right]_{2}$ and $J=-86 \mathrm{~cm}^{-1}$ for $\left[(\mathrm{FeHEDTA})_{2} \mathrm{O}\right]^{2-}$. It may be hoped that the large difference in the magnetic behavior of the two types of model compounds will prove useful in making structural assignments in other dimeric ferric complexes.

The Mössbauer spectra of $\left(\mathrm{Fe}(\mathrm{pic})_{2} \mathrm{OH}\right]_{2}$ and [en $\left.\mathrm{H}_{2}\right]-$ [(FeHEDTA $\left.)_{2} \mathrm{O}\right] \cdot 6 \mathrm{H}_{2} \mathrm{O}$ are also substantially different. The quadrupole splitting constant for the former complex at $80^{\circ} \mathrm{K}$ is $1.00 \mathrm{~mm} \mathrm{sec}-1$, whereas for the oxobridged complex it is $1.7 \mathrm{~mm} \mathrm{sec}-1$. Although the quadrupole splitting is not as large for the dihydroxobridged complex, nevertheless its magnitude indicates a substantially asymmetric coordination environment.

Finally, we turn to a comparison of magnetic and spectral data for $\left[\mathrm{Fe}(\mathrm{pic})_{2} \mathrm{OH}\right]_{2}$ and the dimer formed upon base hydrolysis of aqueous ferric nitrate or perchlorate, which has previously been formulated ${ }^{1,4,9}$ as a dihydroxo-bridged species. Anderegg has pointed out ${ }^{4}$ that $\left[\mathrm{Fe}(\mathrm{pic})_{2} \mathrm{OH}\right]_{2}$ and the aquo dimer must have a similar bridging structure, because they exhibit similar electronic spectral bands at 342 and $335 \mathrm{~nm}$, respectively. Our proof here that $\left[\mathrm{Fe}(\mathrm{pic})_{2} \mathrm{OH}\right]_{2}$ is a dihydroxo-bridged species would thus appear to confirm that the aquo dimer is in fact $\mathrm{Fe}_{2}(\mathrm{OH})_{2}{ }^{4+}$. We note, however, that the room-temperature magnetic moment which has been estimated ${ }^{1}$ for the aquo dimer is substantially lower than that measured directly for the crystalline $\left[\mathrm{Fe}(\mathrm{pic})_{2} \mathrm{OH}\right]_{2}$ model complex, and further work on the former system is needed.

Acknowledgments. Research at the California Institute of Technology was supported by the National Science Foundation; research at Rutgers University

(9) L. N. Mulay and P. W. Selwood, J. Am. Chem. Soc., 77, 2693 (1955). 
was supported by the Petroleum Research Fund and the Rutgers University Research Fund. We thank Professors R. Herber and J. Potenza for the Mössbauer and $\mathrm{X}$-ray crystallographic measurements.

Harvey J. Schugar Department of Chemistry, Rutgers University New Brunswick, New Jersey

George R. Rossman, Harry B. Gray

Contribution No. 3860 Arthur Amos Noyes Laboratory of Chemical Physics California Institute of Technology Pasadena, California 91109

Received May 9, 1969

\section{Electron Spin Resonance of Alkyl Radicals from Bicyclobutanes}

Sir:

Considerable interest in the chemical and physical properties of the $\mathrm{C}_{4} \mathrm{H}_{6}$ hydrocarbon bicyclobutane has been aroused by its highly strained configuration ${ }^{1}$ and interesting structural ${ }^{2}$ and bonding possibilities. ${ }^{3} \mathrm{We}$ wish to report on electron spin resonance (esr) studies of the $\mathrm{C}_{4} \mathrm{H}_{5}$ free radical derived from bicyclobutane in solution. Although bicyclobutane undergoes facile free-radical addition across the 1,3 bond, ${ }^{4}$ the $\mathrm{C}_{4} \mathrm{H}_{5}$ radical can be generated by hydrogen abstraction with $t$-butoxy radical. ${ }^{5}$

Previous studies showed that photochemically generated $t$-butoxy radicals from di-t-butyl peroxide can be employed to produce alkyl radicals from a variety of

$$
\left(\mathrm{CH}_{3}\right) \mathrm{CO} \cdot+\mathrm{RH} \longrightarrow \mathrm{R} \cdot+\left(\mathrm{CH}_{3}\right)_{3} \mathrm{COH}
$$

hydrocarbons directly in the cavity of the spectrometer. ${ }^{7}$ An intense and well-resolved esr spectrum (Figure 1)

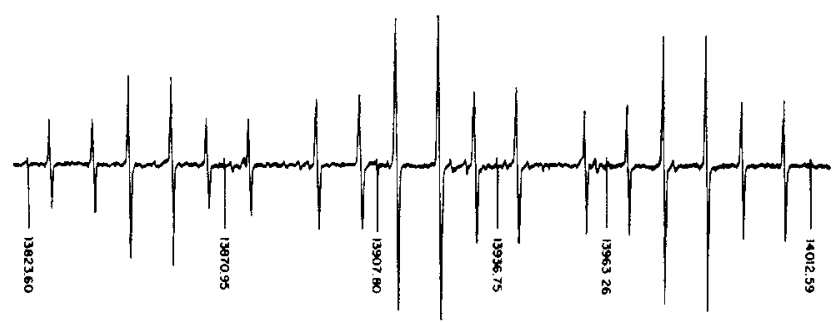

Figure 1. The esr spectrum of cyclobutenyl radical I from bicyclobutane at $-90^{\circ}$. The proton nmr field markers are in kcps.

was obtained when a dilute solution $(c a .10 \% \mathrm{v} / \mathrm{v})$ of di-tbutyl peroxide in the binary system consisting of equal volumes of bicyclobutane and cyclopropane ${ }^{8}$ was irradiated at $-90^{\circ}$ in the esr cavity. The identical spectrum was obtained when cyclobutene was treated under these conditions with $t$-butoxy radicals. We identify

(1) K. B. Wiberg, Record Chem. Progr., 26, 143 (1965); K. B. Wiberg, G. M. Lampman, R. P. Ciula, P. S. Connor, P. Scherfler, and J. Lavanish, Tetrahedron, 21, 2749 (1965).

(2) M. D. Harmony and K. Cox, J. Am. Chem. Soc., 88, 5049 (1966)

(3) M. Pomerantz and E. W. Abrahamson, ibid., 88, 3970 (1966).

(4) E. P. Blanchard, Jr., and A. Cairncross, ibid., 88, 487 (1966).

(5) $t$-Butoxyl is generally the radical of preference for hydrogen abstraction even from alkenes. ${ }^{\circ}$

(6) C. Walling and W. Thaler, J. Am. Chem. Soc., 83, 3877 (1961); J. K. Kochi, ibid., 84, 774 (1962)

(7) P. J. Krusic and J. K. Kochi, ibid., 90, 7155 (1968)

(8) Cyclopropane and ethane are used as inert solvents in these experiments.
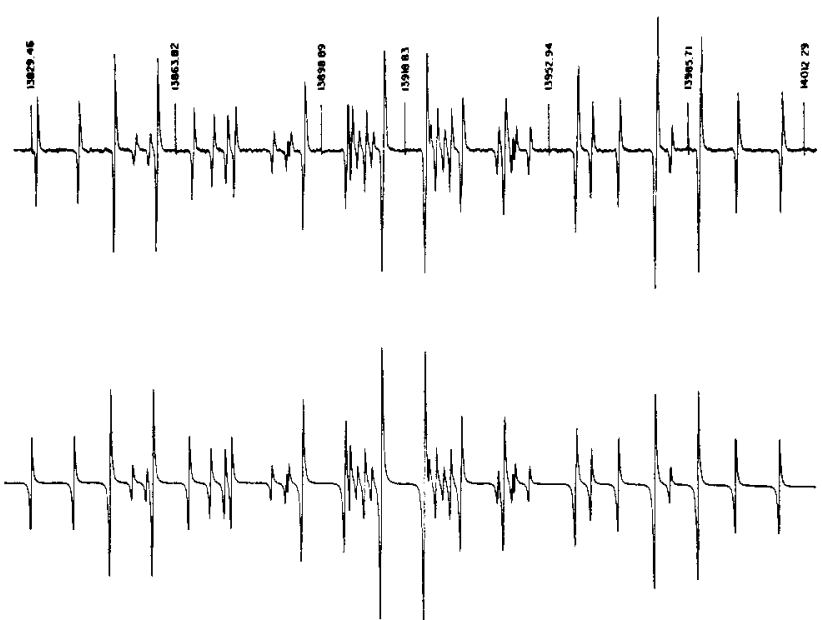

Figure 2. The esr spectrum obtained from bicyclobutane at $-170^{\circ}$. The minor components of the spectrum are associated with the radical species II. The computer-simulated superposition of the two spectra is shown below.

the paramagnetic species as the cyclobutenyl radical I. The hyperfine coupling constants obtained for I are: $a_{\mathrm{H}_{1}}=2.41 \mathrm{G}$ (doublet), $a_{\mathrm{H}_{2}}=15.20 \mathrm{G}$ (triplet), $a_{\mathrm{H}_{3}}$ $=4.45 \mathrm{G}$ (triplet). Fessenden ${ }^{9}$ has recently reported

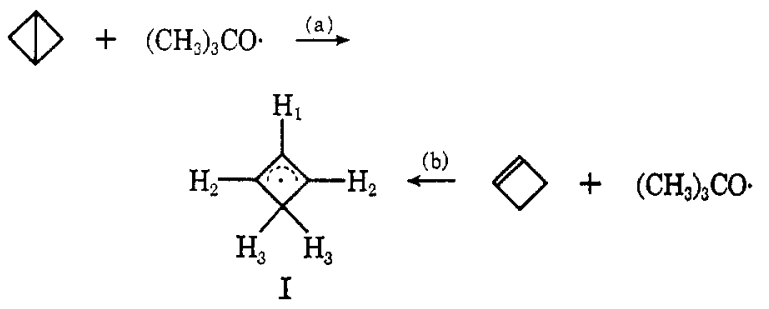

that the magnitude of the coupling constant for the central hydrogen $\left(\mathrm{H}_{1}\right)$ in allylic moieties decreases with the internal angle. Our value for the cyclobutenyl radical is consistent with this trend. The coupling constant for $\mathrm{H}_{2}$ is comparable to that obtained for analogous alicyclic and acyclic allylic radicals. ${ }^{9,10}$ Interestingly, the small value found for $\mathrm{H}_{3}$ confirms Whiffen's prediction based on molecular orbital theory. ${ }^{11}$

At temperatures below approximately $-100^{\circ}$, the esr spectrum consisted of additional lines due to a second paramagnetic species II (Figure 2) with a slightly larger $g$ value $(\Delta g=0.00012)$. Its importance increased as the temperature was lowered to $-170^{\circ}$. Such low temperatures could be achieved without crystallization with the ternary system consisting of equal volumes of bicyclobutane, cyclopropane, and ethane. ${ }^{8}$ The spectrum of 24 lines was readily analyzed into a doublet $\left(a_{\mathrm{H} \alpha}=12.64 \mathrm{G}\right)$ of triplets $\left(a_{\mathrm{Hbr}}=4.40 \mathrm{G}\right)$ further split into two doublets of 7.85 and $0.81 \mathrm{G}$ due to endo and exo hydrogens. A unique assignment for the latter pair cannot be made rigorously at this juncture (vide infra). The most reasonable structure for II is given in Figure 3.

(9) R. W. Fessenden, 156th National Meeting of the American Chemical Society, Atlantic City, N. J., Sept 9, 1968, Abstract No. ORGN-85.

(10) J. K. Kochi and P. J. Krusic, J. Am. Chem. Soc., 90, 7157 (1968); unpublished results.

(11) D. H. Whiffen, Mol. Phys., 6, 224 (1963). See also W. T. Dixon, Chem. Commun., 559 (1969). 